\title{
Proje Tabanlı Öğrenme Yönteminin Fen ve Teknoloji Derslerinde Uygulamaları Hakkında Öğretmen ve Veli Görüşlerinin İncelenmesi
}

\begin{abstract}
İsmail KILIÇ*
Mehtap ÖZEL ${ }^{* *}$

Öz

Bu araştırmanın amacı, İlköğretim 2. Kademe Fen ve Teknoloji derslerinde Proje Tabanlı Öğrenme yönteminin uygulanma sürecini öğretmen ve veli görüşleri bakımından incelemektir. Araştırma, nitel araştırma yöntemlerinden durum (vaka) çalışması ile gerçekleştirilmiştir. Araştırmanın verileri 11 Fen ve Teknoloji dersi öğretmeni ve 23 veliyle yarı yapılandırılmış görüşmeler yapılarak elde edilmiştir. Veriler nitel araştırma yöntemlerindeki veri analiz metotlarından biri olan betimsel analize tabi tutularak araştırmanın bulgu ve sonuçları elde edilmiştir. Araştırmanın sonucunda öğretmen ve velilerin projeye kavramına dair ortak görüşlerinin, yeni bir ürün tasarlamak veya üretmek olduğu tespit edilmiştir. Çalışma grubundaki öğretmenlerin Proje Tabanlı Öğrenme yöntemini okullarda sınıf mevcutlarının kalabalık ve müfredatın çok yoğun olduğu olması gibi nedenlerden kaynaklanan sorunlar yüzünden bu yöntemi olarak uygulanabilir bulmadıkları anlaşılmıştır. Ayrıca öğretmenlerin projeleri değerlendirirken öğrencilerin göstermiş oldukları çabaları ölçüt aldıkları görülmüştür. Okulda proje konusunun seçimiyle başlayan proje süreçlerin diğer aşamalarının öğrencilerin evinde ailelerinin yardımıyla gerçekleştirildiği, ailelerin proje çalışmalarının öğrenciler için faydalı olduğunu düşündüğü, çocuklarını desteklediği görülürken bazı velilerin yüksek not kaygısı nedeniyle çocuklarının projelerini yaptıkları sonucuna ulaşılmıştır.
\end{abstract}

Anahtar Kelimeler: Fen ve Teknoloji dersi, Proje Tabanlı Öğrenme Yöntemi, öğretmen görüşleri, veli görüşleri

\section{A Research on Views of Teachers and Parents About Application of Project Based Learning Method in Science And Technology Classes}

\begin{abstract}
The aim of this study is to analyze the application process of Project-Based Learning method in Primary School Second Grade Science and Technology course in terms of teacher and parent. The study was carried out through case study being one of the qualitative research methods. The data were gathered from semi-structured interview forms carried out with 11 Science and Technology
\end{abstract}

* Yrd. Doç. Dr., Trakya Üniversitesi, İlköğretim Bölümü, iso_kilic@hotmail.com

** Öğretmen, MEB, Ataşehir Leman Ana İHO-İstanbul, mehtapozel.34@gmail.com 
teachers of five state schools and 23 parents. The data gathered from this study were analyzed with descriptive analysis method. The findings gathered from the study were interpreted in order to give meaning to data, to explain the relationship between the findings and to draw conclusion. Even though the teachers in the study group see the PBL method as a need to be applied in the classes, the study revealed out that they found this method inapplicable because of crowded classes and intensive curriculum. Also, the study revealed out that the teachers considered the efforts of the students as a criteria during Project assessment. Also, the study revealed out that the latter processes of the Project starting with identifying Project topic were carried out with the help of their families and the families thought that the Project studies were beneficial fort he students and they supported their children; however some parents did the Project of their children with the concern of high score.

Keywords: Science and Technology course, Project Based Learning Method, Teacher Opinions, Parent Opinions.

\section{GİRIŞ}

Fen ve Teknoloji dersinde yapılan fen eğitiminin en önemli amacı öğrencilerin, yeni bir problemle karşılaştıklarında onu çözmelerine, ilke ve kavramları anlamalarına yardımcı olmaktır (Kaptan ve Korkmaz, 2001). Bu da öğrencilere üst düzey zihinsel süreçlerin kazandırılmasıyla mümkün olacaktır. Proje yaklaşımı öğrenciyi öğretimin merkezine alan bir öğrenme ve öğretme yaklaşımıdır. Bu yaklaşımın temel amacı, öğrenilecek olan konunun öğrenci tarafından bir sorun olarak ortaya konulması, araştırılması ve çözüm önerileri getirilmesidir (Karakuş, 2004).

Proje Tabanlı Öğrenme yönteminde öğrenciler kendi öğrenmelerinden sorumludur. Bu yöntemin, kullanıldı ̆̆ derste öğrencilerin işbirliği içerisinde problem çözme yetenekleri ve yaratıcılıkları gelişir. Proje çalışması yapılırken öğrencinin bilgi ve beceri edinmesi amaçlanır. Öğretmenler öğrencilerini takip ederken, öğrencilerinin proje çalışmasında olası ihtiyaçlarının neler olduğunu veya onların proje yapımındaki herhangi bir sorunu nasıl çözmeye çalıştıklarını izlerler (Demirel, 2005; Yıldız, 2007). Proje Tabanlı Öğrenme sürecindeki roller sadece öğretmen ve öğrenciler tarafından paylaşılmamaktadır. Bu sürecin önemli bir parçasını da aileler oluşturmaktadır (Güvey, 2009). Proje çalışmalarında aileler çocuklarının öğ- renmelerini takip edeceği ve onları destekleyeceği için bu yöntemde rolleri çok büyüktür. Proje çalışmaları hazırlanırken öğretmenler, öğrenci ve veliyle işbirliği yapmalıdır (Kaptan ve Korkmaz, 2001).

Proje Tabanlı Öğrenme yaklaşımının fen eğitiminde uygulanmasıyla ilgili çok sayıda çalışma olmasına rağmen; öğretmen ve veli görüşlerinin bir arada olduğu araştırmaların yetersiz sayıda olduğu gözlemlenmiştir. Dolayısıyla bu araştırmanın öğretmen ve veli görüşlerinin incelenecek olması, Fen ve Teknoloji dersinde kullanılan Proje Tabanlı Öğrenme yaklaşımının öğretmenleri ve velilerini nasıl etkilediğinin anlaşılmasına, Fen ve Teknoloji dersi öğretimi ile ilgili yapılacak çalışmalara katkısının olabileceği düşünülmektedir.

\section{YÖNTEM}

$\mathrm{Bu}$ araştırmanın problemini Fen ve Teknoloji derslerinde Proje Tabanlı Öğrenme yönteminin uygulanma sürecine dair öğretmen ve veli görüşlerinin nasıl olduğu sorusu oluşturmaktadır. Yapılan bu çalışmada; Fen ve Teknoloji derslerinde proje çalışmalarına yönelik öğretmenlerin ve velilerin bakış açısı, proje kavramı hakkında ne kadar bilgi sahibi oldukları, öğretmenlerin projeleri değerlendirirken nasıl bir yol izledikleri, velilerin çalışmalardaki konumunun ortaya çıkarması amaçlanmıştır. 
Araştırma, nitel araştırma yöntemlerinden durum (vaka) çalışması ile gerçekleştirilmiştir. Araştırmada, veri toplama aracı olarak yarı yapılandırılmış mülakat formları kullanılmıştır. $\mathrm{Bu}$ formlar, verilerin hizlı kodlanmasına ve analiz edilmesine imkân tanıması, katılımcıların verdikleri bilgiler arasındaki benzerlik ve farklılıkları karşılaştırmaya yardımcı olması gibi özellikleri nedeniyle kullanılmıştır (Çepni, 2010; Büyüköztürk, Kılıç, Akgün, Karadeniz ve Demirel, 2012).

Geliştirilen mülakat formlarının geçerlilik, güvenilirlik ve kullanışlılığının artırılması amacıyla ön çalışma yapılmıştır. Bu görüşme formundaki sorular araştırmanın amacı dikkate alınarak belirlenmiştir. Formun geliştirme sürecinde kapsam geçerliliğini sağlamak amacıyla literatürden yararlanılmış ve program incelemesi yapılmıştır. Hazırlanan formların kapsam ve yapı geçerliliğini sağlamak için öncelikle Trakya Üniversitesi Eğitim Fakültesinde bulunan uzman akademisyenle tartışılarak şekillendirilmiş ve araştırmanın çalışma grubunu belirlemek için oluşturulan çalışma grubu havuzu içerisinden rastgele seçilen iki Fen ve Teknoloji öğretmenine, iki veliye uygulanmıştır. Ön çalışma sonucunda ortaya çıkan sonuçlar tekrar gözden geçirilerek mülakat formlarına son şekli verilmiştir. Bu formlardaki hedef sorular görüşmeciye rehber olması amacıyla kullanılmıştır.

Araştırmanın verileri 2010-2011 eğitim Öğrenme yılında İstanbul ili Ataşehir ilçesinde bulunan beş devlet okulundaki 11 Fen ve Teknoloji öğretmeni ve 23 veliyle yarı yapılandırılmış görüşmeler yapılarak elde edilmiştir.

Katılımcıların mülakat sorularına verdikleri cevaplar nitel veri analizini kolaylaştırması ve araştırmanın güvenilirliğini artırması için ses kayıt cihazları ile kaydedilmiştir. Öğretmenlerle yapılan görüşmeler ortalama 30-
35 dakika, velilerle yapılan görüşmeler 20-25 dakika sürmüştür. Görüşmeler yapılmadan önce katılımcıların izni alınmıştır. Görüşmeler okullarda bulunan müdür yardımcisı ve memur odalarında, toplantı salonlarında, fen teknoloji laboratuvarlarından ve konferans salonlarında yapılmıştır. Ortamların sessiz, her türlü dikkat dağıtan unsurlardan arınmış olmasına özen gösterilmiştir. Katılımcılara randevular alınarak, birebir araştırmacı tarafından görüşmeler yapılmıştır.

Görüşmelerden elde edilen verilerin analizi için nitel araştırmalarda kullanılan veri analiz yöntemlerinden biri olan betimsel analiz yönteminden faydalanılmıştır. Nitel araştırmalarda betimsel ve içerik analizi olmak üzere iki veri analiz süreci bulunmaktadır. Betimsel analizde amaç; görüşme ve gözlem sonucu elde edilen verilerin düzenlenmiş ve yorumlanmış bir şekilde okuyucuya sunulmasıdır. Veriler daha önceden belirlenmiş temalara göre sınıflandırılır, özetlenir ve yorumlanır. Bulgular arasında neden-sonuç ilişkisi kurulur ve gerekirse olgular arasında karşılaştırmalar yapılır (Yıldırım ve Şimşek, 2011). Betimsel analiz; betimsel analiz için bir çerçeve oluşturma, tematik çerçeveye göre verilerin işlenmesi, bulguların tanımlanması, bulguların yorumlanması olmak üzere dört aşamadan oluşur (Altunışık, Çoşkun, Yıldırım ve Bayraktaroğlu, 2010). Bu aşamalar takip edilerek araştırmanın bulguları elde edilmiştir.

Katılımcıların kimlik bilgilerinin korunması amacıyla, isimleri kullanılmamıştır. Velilere görüşülme sırasına göre $V 1, V 2, \ldots$; öğretmenlere Ö1, Ö2..., şeklinde kod numaraları verilmiştir. Kodlamanın güvenirliliği için Miles ve Huberman (1984) ilkelerinden yararlanılmıştır. $\mathrm{Bu}$ ilkeler görüşmelerde elde edilen verilerin azaltılması, ham verinin önemli kısımlarının seçimi, belli kısımlara odaklanma, basitleştirme, özetleme ve dönüştürmedir. Bu maksatla 
rastgele seçilen örnekler üzerinde araştırmacı ve iki uzman ayrı ayrı kodlama yapmış ve sonuçlar karşılaştırılarak kodlamanın ön yarg1 ve yanlış anlamadan uzak, ortak bir anlayışa göre yapılması sağlanmıştır. Kodlar arasındaki ilişkiler incelenerek, benzerlik ve farklılıklar saptanmıştır. Ayrı ayrı oluşturulan kategorilerin kodlama tutarlılığına bakılmıştır. Daha sonra araştırmacı ve iki uzmanın değerlendirmeleri öğretmen ve veli sorularına verilen cevaplara bakılarak "Görüş Birliği" ve "Görüş Ayrılı̆̆gı" şeklinde gruplandırılmıştır. Uyuşum yüzdesi hesaplama formülünden yararlanılarak araştırmanın güvenirliği hesaplanmıştır. Uyuşum yüzdesi, gözlemcilerin veya değerlendiricilerin uyuştukları madde sayısının toplam değerlendirme veya gözlem sayısına olan oranıdır (Türnüklü, 2000). Yapılan hesaplamalarda araştırmacı ve iki uzman arasındaki uyuşum yüzdesi öğretmenler ve veliler için \% 87,5 olarak bulunmuştur. Elde edilen değerin güvenilir kabul edilebilmesi için uyuşum yüzdesinin \%70'in üzerinde olması gerekmektedir (Şencan, 2005). Bu değerlere bakılarak yapılan araştırmanın güvenilir olduğu söylenebilir.

\section{BULGULAR}

$\mathrm{Bu}$ bölümde öğretmenlere ve velilere sorulan sorulardan bazılarına yer verilmiştir. Veli ve öğretmenlerle yapılan yarı yapılandırılmış görüşmelerden elde edilen verilere anlam kazandırmak için bulgular düzenlenerek yorumlanmıştır. Araştırmada kodlar, frekanslarıyla birlikte tablolara yerleştirilmiş ve yüzdelik olarak da gösterilmiştir. Ayrıca çalışma grubunda bulunan bazı öğretmen ve veli görüşlerine verilmiştir.

Soru 1: Sizce proje nedir?

Tablo 1. Soru 1'e velilerin vermiş olduğu cevaplara göre f ve \% değerleri

\begin{tabular}{l}
\hline KODLAMA \\
\hline Beceriyi artırmak için yapılan çalışmadır. \\
Ödevdir. \\
Hayal gücü \yaratıcılıktır. \\
Ön çalışmadır. \\
Yorumsuz
\end{tabular}

Tablo 1 incelendiğinde velilerin projeyi; beceriyi artırmak için yapılan çalışma, ödev, hayal gücü\yaratıcılık, bir ön çalışma olarak nitelerken, bazılarının ise yorum yapmadığı görülmüştür.

V22: "Yeni şeyler öğrenmek için çocŭ̆un becerisini, bilgisini daha çok geliştirmek için verilen ödevdir." V10: "El becerisi geliştirmesidir, güzel bir şeydir. Çocuk kafa yoruyor. Ne olsa ondan bir şeyler üretir. Yani sizin bir şey olmaz dediğiniz şeyden yeni bir şeyler üretiyor.

V14: "Yeni şeyler öğrenmek için, çocuğun bilgi ve becerisini yükseltmek için yapulan ödevdir. Yani projenin en önemli özelliği araştırma yapmaktır ve öğrenciye yeni fikirler buldurmasıdır."

$\begin{array}{lc}\text { f } & \% \\ 8 & 34,7 \\ 6 & 26,2 \\ 5 & 21,7 \\ 2 & 8,7 \\ 2 & 8,7 \\ \text { Veliler, proje çalışmaları sürecinde öğrencilerin } \\ \text { yeni bir şeyler hazırlamak için el yatkınlığının, } \\ \text { düşünce becerilerinin, } \text { üretkenliğini artırmak } \\ \text { için çalışmalar yaptığını ifade etmişlerdir. Bu } \\ \text { durumunda veliler açısından proje kavramına } \\ \text { dair öne çıkan görüşün (34,7) beceriyi artırmak } \\ \text { için yapılan çalışma olduğu görüşüne önemli } \\ \text { bir etkisi olduğu söylenilebilir. }\end{array}$

Soru 2: Sizce projelerin öğrencilere faydası var mıdır? Nedenlerini açıklayınız. 
Tablo 2. Soru 2'ye velilerin vermiş olduğu cevaplara göre f ve \% değerleri

\begin{tabular}{llll}
\hline KODLAMA & & $\mathbf{f}$ & $\mathbf{\%}$ \\
\hline Var. & Zihinsel gelişim & 12 & 52,0 \\
$(\% 78)$ & Psikomotor gelişim ve zihinsel gelişim & 4 & 17,3 \\
& Psikomotor gelişim & 2 & 8,7 \\
\hline Yok. & Aile yapiyor & 3 & 13,3 \\
$(\% 22)$ & *Diğer & 2 & 8,7 \\
\hline
\end{tabular}

${ }^{*}$ Frekansı ikiden az olan değerler gösterilmemiştir

Çalışma grubundaki velilerin büyük bir kesimine (\%78) göre projeler, öğrencilerin zihinsel ve psikomotor gelişimleri için faydalı olduğunu, bu yüzden de proje çalışmalarını öğrencilere olumlu katkısı olduğunu düşündüğü görülmüştür. Diğerler velilerin (\%22) ise proje çalışmalarının daha çok ailelerin yaptığını bu yüzden de öğrencilere herhangi bir katkısı olmadığını düşündükleri anlaşılmıştır. Yukarıda belirtilen soruya velilerin verdiği cevaplardan bazıları aşağıda gösterilmiştir.

V13: "Çok büyük faydası var bence. Çocuklar yaptıkları projelerin çalışıp çalışmayacă̆ını anlıyorlar ve bu bilgilerini hayata uygulamaya çalışıyorlar."

V12: "Keskinlikle faydası var. Çok zekâ geliştirici kesinlikle bir şeydir. Çok daha özenli çok daha güzel çalışıyor, öğrendiklerini uygulayabiliyor."

V18: "Var. Mutlaka faydası olmaz olur mu? Mesela ben bu projeyi yaptı̆̆ rum. Onun daha çok hoşuna gidiyor, daha çok gayret ediyor. Bugün o raporluydu, ama saati kurmuş, sabah altıda okula gelmek için. Okulda proje yapacakmış diye bence bu projeler okulları çocuklara sevdiriyor."

Ancak bazı velilerin ise proje çalışmalarının öğrenciler için faydalı olmadığı görüşünde oldukları tespit edilmiştir ve bu görüşlerden bazılarına ise aşağıda yer verilmiştir

V4: "Bence faydası yok öğretmenler eve ders, ödev vermiyorlar. Proje veriyorlar yapin gelin diyorlar. Öğrencilere zor geliyor. Evde aile yapıyor, çocuk oturuyor, biz yapıyoruz."
V7: "Faydalı olduğunu pek sanmıyorum. Çocuklar zor projeleri zaten tek başlarına yapamıyorlar. Bu yıl pek proje yapılmadı. Geçen yıl ampul takma ışık yapma çalışan bir saat gibi şeyler yapıyorlard. Çocuklar için zor ödevler verildiğini düşünüyorum ama bulunduğumuz yer açısından her malzemeye ulaşma imkânımız yok öğrenci evde bir şeyler yapmak istediğinde yapmıyor ayrıca bu projeler okullarda öğretmenler gözetiminde yapılmalı evde yapmamalılar."

V15: "Projeyi öğrenciler tam olarak algılamıyor, eskiden dönem ödevleri vardı şimdi projeleri aynı o dönem ödevleri gibi algılıyor çocuklar. Bu yüzden özgün bir ödev çıkmıyor. Türkiye'nin geneline bakıldı̆̆ııda bu proje ödevlerini kendilerin yaptıklarına inanmıyorum ayrıca bunu böyle olduğunu bir öğretmen olarak, bir baba olarak gözlemliyorum. Çocuk bu ödevinde ailesinden yardım alabilir, almalı! Ama aileler bunu çok abartıyor. Ödevlerin yaklaşık \%80'ini veliler yapıyor. Ödevlerin yaklaşık $\% 80$ nini veliler yapıyor. Geçenlerde kızımın sınıfna din öğretmeni proje ödevi vermişti. Ödevlerin teslim gününde baktım okula veliler ellerinde projelerle geliyorlar ama öyle projeler var ki onları öğrencilerin yapmadı̆̆ı çok açık. Aileler resmen proje yarışına giriyor, bu durumda en çok öğrencilere zarar veriyor. Bir öğretmen, bir baba olarak çocukların eşit bir şekilde değerlendirilmediğini düşündüğ̈̈m için projeye olumsuz bakıyorum."

Projelerin öğrencilere faydalı olmadığını düşünen veliler ise öğrencilerin projeleri kendilerinin yapmadığ olarak verilen proje çalışmalarının öğrencileri- 
nin kapasitelerinin üstünde olmasının da bu duruma neden olduğunu ifade etmişlerdir. Ayrıca projeler için gerekli malzemelerin temininde sıkıntılar yaşandı ğı veliler tarafından dile getirilmiştir. Ailelerin proje yapım sürecinde çocuklarının proje ödevlerini nerdeyse tümünü yaptıklarını, bir yarış içerisine girerek çocuklarının en yüksek notları alması için çalıştıkları anlaşılmıştır.

Soru 3: Proje denilince ne anliyorsunuz?

Tablo 3. Soru 3'e öğretmenlerin vermiş olduğu cevaplara göre f ve \% değerleri

\begin{tabular}{lll}
\hline KODLAMA & $\mathbf{f}$ & \% \\
\hline Yeni ürün tasarımı ve üretimidir. & 7 & 63,1 \\
Sorun çözümüdür. & 3 & 27,9 \\
Ödevdir. & 1 & 9,0 \\
\hline Öğretmenlere proje kavramından ne anladıkla- & Onların düşüncelerine ve kapasitelerine göre yapa- \\
rı sorulduğunda verdikleri cevaplar Tablo 3’te & bilecekleri yeni ürünler diye bakıyorum." \\
görüldüğü gibi üç kategoride toplanmıştır. Bu & Ö11: “Proje insanların değişik fikirlerini ortaya \\
kategorilerden projeyi yeni bir ürün tasarımı ve & koymasıdır. İnsanın kendini, düşünce yeteneğini \\
üretimi olarak gören öğretmenler çoğunluğu & geliştirmesi, hayal gücünü geliştirmesidir.” \\
oluşturmaktadır. & Araştırmaya katılan öğretmenlerin proje kav- \\
Ö1: "Proje, öğrencilerin veya insanların yeni bir şey & ramını yeni ürünler ortaya çıkarmak, hayal \\
üretmesi, olmayan bir şeyi kendi kafasından ürete- & gücünün geliştirmek, hayatta sorun olan bazı \\
bilmesidir.” & şeyleri çözüme ulaştırmak şeklinde tanımladık- \\
Ö4: “Proje hayatımızda sorun olan bazı şeyleri & ları görülmüştür. \\
çözüme ulaştırmak.” & Soru 4: Proje Tabanlı Öğrenme yönteminin \\
Ö10: "Proje daha önce denenmemiş, yapılmamış & okullarda uygulanabilirliği hakkında ne \\
çocukların seviyesinde yapabileceği yeni ürünler. & düşünüyorsunuz?
\end{tabular}

Tablo 4. Soru 4'e öğretmenlerin vermiş olduğu cevaplara göre f ve \% değerleri

\begin{tabular}{lll}
\hline KODLAMA & f & \% \\
\hline Uygulanamaz. & 9 & 81,8 \\
Uygulanabilir. & 2 & 18,2 \\
\hline
\end{tabular}

Tablo 4'e bakıldı̆̆ında öğretmenlerin \% 81,8'inin Proje Tabanlı Öğrenme yönteminin okullarda uygulanabilir bir yöntem olarak değerlendirmediği anlaşılmaktadır. Öğretmenlerin görüşlerinden bir kaçına aşağıda yer verilmiştir.

Ö1: "Bu yöntemi uygulayamıyoruz. Eğger milli eğitim sınıfları 20-25 kişilik yaparsa bu yöntemi rahat uygulayabiliriz, öğrencilere çok faydalı bir şeydir. Tabi ki bunu yapmak için müfredatın biraz hafifletilmesi gerekiyor. Müfredatın daha az ve öz olması gerekiyor ve gereksiz çok fazla konu var. Müfredat 6 ve 7.sinıflarda ciddi anlamda çok kalaba- lık. Ĕğer proje tabanl öğrenme yöntemini uygulamak istiyorsak, öğrencilerin yaparak yaşayarak ögrrenmesini istiyorsak müfredatın ve sinıf mevcudunun azaltılması gerekiyor.40-50 kişilik sınıflarda bunun uygulanması imkânsız. Derslerde bu yöntemi uygulayamıyorum. Ders dışında, okul genelinde ekstra bir sınıf açıyoruz. 20-25 kişilik oluşturuyoruz. Tüm bu çalışmaları ders dışında yapıyoruz. Derslerde verilen sürede bunları yapabilmek imkânsız."

Ö2: "Kendi okulum için söyleyeyim; bunu için sınıf mevcudunu 20'den az yani en fazla 20 olmasi gerekiyor. 20'den fazla mevcudu olan sinıflarda uygula- 
nabileceğini kesinlikle düşünmüyorum. Benim okulumda ise sinıf mevcudu 47 hatta 49 kişilik. Burada uygulama çok mümkün değil, uygulandı̆̆ zaman müfredat să̆liklı olmuyor. Bir yerde mutlaka tıkaniyor."

Ö6: "Bence uygulanmyor. Bunun temelden olması gerek yani anasinfindan itibaren proje tabanl ĕgitim olacak ki; o zaman tam olarak sinıflanır. Bilimsel proje daha farkl, onu bilen öğrenci çok çok az."

Araştırmadaki öğretmenlerin (\% 81,8) çoğunluğu Proje Tabanlı Öğrenme yöntemini okul- larda uygulanamayacak bir yöntem olduğunu belirtmişlerdir. Öğretmenlere göre Proje Taban11 Öğrenme yöntemini uygulanamamasına sebebine bakıldığında; sınıf mevcutlarının kalabalık ve müfredatın çok yoğun olduğu olmasından, öğrencilerde genele olarak proje alışkanlığının ve ders zamanın yeterli olmamasından kaynaklanan sorunların olduğu anlaşılmıştır.

Soru 5: Öğrencilerin hazırladıkları projeleri nasıl değerlendiriyorsunuz?

Tablo 5. Soru 5'e öğretmenlerin vermiş olduğu cevaplara göre f değerleri

\begin{tabular}{ll}
\hline KODLAMA & f \\
\hline Emek & 10 \\
Kullanışlılık, işlevsellik & 8 \\
Özgünlük & 4 \\
Düzen, estetik & 3 \\
Kaynak taraması & 3 \\
\hline
\end{tabular}

*Birden fazla tema aynı anda belirtildiği için sadece frekans değerleri gösterilmiştir.

Tablo 5.'e bakıldığında öğretmenlerin projeleri değerlendirirken daha çok verilen emek ve kullanışlı, işlevsel olmasına dikkat ettikleri görülmektedir. Öğretmenlerin projeleri nasıl değerlendirdiklerine dair görüşlerine aşağıda yer verilmiştir.

Ö1: “Özgün ve faydalı olması olmasına dikkat ediyorum kendi değerlendirme formum var. Onda belirlediğim projenin düzeni, projeye verilen emek gibi çeşitli kriterlerim var. Bu kriterlere göre değgerlendiriyorum."

Ö6:"Projeye verdikleri emek ve orijinalliği benim için önemli ona göre değerlendiriyorum. Ayrıca kendi değerlendirme ölçeğim var onu kullanıyorum."

Ö9: “ Gerekli araştırmaları yapmış mı? Kimlerden yardım almış ve ne kadar yardım almış? Bunlara önem veriyorum. Proje özgün mü, bir işlevi var mı? Bunlar genelde kriterlerim."
Öğretmenler projeleri değerlendirirken; projenin düzenine, estetiğine, özgünlüğüne önem verdikleri ayrıca yapılan kaynak taramasını da dikkate aldıkları anlaşılmıştır.

\section{SONUÇ VE TARTIŞMA}

Araştırmanın sonucunda öğretmen ve velilerin ortak görüşlerinin; projenin yeni bir ürün tasarlamak veya üretmek olduğu şeklinde tespit edilmiştir. Proje kavramına ilişkin alan yazına bakıldığında projenin; tasarı ya da tasarı geliştirme, hayal etme ve planlama, öğrencilerin gerçek yaşama benzer işler üzerinde özgün bir ürün ortaya koymak amacıyla yaptıkları bağımsız konu araştırmaları ve etkinlikler, öğrencileri onlara ilginç gelecek aktivitelerle yoğuran, ders konusuyla ilgili olan yoğun deneyimler, genel olarak ortaya konacak bir iş ve elde edilecek bir sonuç ile ilgili bir düşünce olarak 
nitelendirildiği görülmüştür (Coşkun, 2004; Erdem, 2002; Öncül, 2000; Geocities, 2007; MEB, 2008). Araştırmaya katılan öğretmen ve velilerin proje kavramıla ilgili görüşlerinin alan yazınıyla benzer olduğu tespit edilmiştir. Buradan yola çıkılarak veli ve öğrencilerde proje kavramına ilişkin doğru bir algının var olduğu düşünülmektedir. Bunlara ek olarak Önen, Mertoğlu, Saka ve Gürdal (2010) çalışmalarında öğretmenlerin hizmet içi eğitimden sonra proje ve Proje Tabanlı Öğrenme yöntemine ilişkin bilgilerine bakılmış öğretmenlerin hizmet içi eğitim çalışmasından sonra projeye kavramına ilişkin “Ürün elde etme, kendi kendine öğrenme ve uygulama yapma" gibi düşünceler ortaya attıklarını tespit etmişlerdir. Ayrıca Baki ve Bütüner (2009)'in yaptıkları araştırmada öğretmenler proje kavramını "Eldeki imkânlarla somut şeyler üretme, çeoresindeki imkânlar; kullanarak derinlemesine bilgi edinme" olarak ifade etmişlerdir. Baki ve Bütüner (2009) ile Önen, Mertoğlu, Saka ve Gürdal (2010)‘n araştırmalarına bakıldığında proje kavramına ilişkin elde ettikleri bulguların bizim araştırmamızın sonuçlarıyla örtüştüğü görülmüştür.

Araştırmadaki öğretmenlerin tamamı derslerinde bu yöntemi uygulayamadıkları görülmüştür. Ayrıca öğretmenlerin büyük çoğunluğunun PTÖ yöntemini, okullarda uygulanamaz bir yöntem olduğunu düşündükleri tespit edilmiştir. Sınıf mevcutlarının kalabalık, ders müfredatının çok yoğun, ders süresinin yetersiz olması ve öğrencilerde genel olarak proje alışkanlığının olmaması bu yöntemin uygulanama nedenleri olarak ortaya çıkmıştır. Yöntemin uygulanabilmesi için öğretmenler, ders müfredatlarının ve sınıf mevcutlarının azaltılması gerektiğini belirtmişlerdir. Ayrıca öğrencilere eğitimin ilk yıllarından itibaren proje yaptırmayı önermişlerdir. Çakan (2005), Şahin (2007), Çoruhlu, Nas ve Çepni (2009), Kaymakçı ve Öztürk (2011)'ün çalışmalarında sınıf mevcutlarının kalabalık olmasının bu yöntemi uygulanmasında sorunlar yaşattığı ve yöntemin uygulanabilmesi için mevcutların azaltılmasını gerektiğine dair bulgularıla; bizim çalışmamızdaki bulgular paralellik gösterdiği anlaşılmıştır.

Araştırmada öğretmenlerin projeleri değerlendirirken daha çok projeye verilen emeğe ve projelerin kullanışlı olmasına değer verdiği görülmektedir. Ayrıca öğretmenlerin, öğrencilerin çevrelerine duyarlığının artmasına, problem çözme ve psikomotor becerilerinin gelişmesine önem verdikleri anlaşılmaktadır. Kütükte (2010) proje çalışmasında öğretmenlerin verilen emeğe dikkat ettiklerini tespit etmiştir. $\mathrm{Bu}$ verilerin araştırmada öğretmenlerin daha çok emeğe dikkat ettiklerine dair sonucumuzu desteklediği görülmüştür. Esen ve Güneş (2012) ise öğretmenlerin proje çalışmalarını değerlendirirken daha çok okul derslerindeki yazılı ve sözlü notlarına göre değerlendirdiklerini tespit etmiştir. Bu durumda Esen ve Güneş (2012)'in çalışmasındaki öğretmenlerin; proje çalışmalarında öğrencilerin proje için verdikleri emeğe dikkat etmedikleri öğrencinin genel durumuna göre puan verdikleri söylenebilir. $\mathrm{Bu}$ bulgu, araştırmaya katılan öğretmenlerin öğrencilerin projelerini verilen emeğe göre değerlendirmediği şeklinde yorumlanabilir.

Araştırmada velilerin proje çalışmalarının öğrenciler için faydalı olduğunu düşündüğü sonucuna ulaşılmıştır. Projelerin öğrencilere faydalı olduğunu düşünen velilere göre projeler, öğrencilerin derslerde öğrendikleri bilgilerin hayata uygulanıp uygulanamayacağ 1 hakkında fikir sahibi olmalarına, zekâ ve el becerilerinin gelişimine olumlu yönde katkıda bulunduğunu belirtmişlerdir. Bu durumun velilerde proje yapımının öğrenciler için faydalı bir çalışma olduğunu düşünmelerinde etkili olduğu söylenilebilir. Elde edilen bu sonucun Güney (2010) "Illköğretim 4-5. Sinıflarda Verilen Proje ve Performans Ödevleriyle Illgili Öğretmen ve Veli 
Görüşleri " adlı çalışmasında öğretmen ve velilerin proje ve performans ödevlerine karşı olumlu tutumları olduğu bulgusuyla paralellik gösterdiği düşünülebilir.

Projeler, öğrencilerin yaptıkları projelerle ilgili konularda ilk elden (yaparak, yaşayarak) bilgi edinmelerini sağlar. Ayrıca projeler bilişsel işlem becerileri (karar alma, eleştirel düşünme, problem çözme vb.), kendi kendini yönetme becerileri (amaçları belirleme, görevleri organize etme, zaman yönetimi vb.), tutumlar (öğrenme sevgisi, ileri eğitim aşamalarına isteklilik), eğilimler (kendini yönlendirme, başarma duygusu), inançlar (kendi kendine yeterlik) gibi alanlarda öğrencilerin yeteneklerini kullanmaları için fırsatlar verir (Yurtluk, 2005; Sezgin, Çalışkan, Çallıca ve Erol, 2002; Korkmaz ve Kaptan, 2002; Dede ve Yaman, 2003; Hsu ve Liu, 2005). Çalışmamıza katılan velilerin ifade ettiği görüşlerden projelerin öğrencilerde "...Çocuklar yaptıkları projelerin çalışıp çalışmayacă̆ım anlıyorlar ve bu bilgilerini hayata uygulamaya çalışıyorlar." projelerin öğrencilerin problem çözme ve bilişsel işlem becerilerini geliştirdiğine, “...Çok zekâ geliştirici kesinlikle bir şeydir. Çok daha özenli çok daha güzel çalışıyor, öğrendiklerini uygulayabiliyor." yaparak yaşayarak öğrendiğine, "Onun daha çok hoşuna gidiyor, daha çok gayret ediyor. Bugün o raporluy$d u$, ama saati kurmuş, sabah altıda okula gelmek için. Okulda proje yapacakmış diye bence bu projeler okulları çocuklara sevdiriyor." okula ve öğrenmeye karşı olumlu tutumlara neden olduğu anlaşılmıştır. Nitekim bu sonuçlarla alanyazın arasında pozitif yönde anlamlı bir ilişki bulmuştur. Dolayısı ile araştırmanın bulguları alanyazın ile tutarlı olduğu söylenilebilir.

Araştırmaya katılan bazı velilerin yüksek not kaygısı nedeniyle çocuklarının projelerini yaptıklarını ifade etmişlerdir. Bu verinin Kaplan ve Coşkun (2012), Ayvacı ve Er Nas (2009), Ersoy ve Anagün (2009), Kurak (2009), Demir
(2008), Yücel (2008) ve Arda (2009)'nın yaptıkları çalışmalarda velilerin proje süreçlerine gereğinden fazla dâhil olduklarına ve öğrencinin rolünü üstlendiklerine dair bulgularla benzerlik gösterdiği görülmüştür. Örtüşen bulgular dolayısıyla bu çalışmamızın desteklendiği söylenebilir.

Ayrıca projeler için gerekli malzemelerin temininde sıkıntılar yaşandığı veliler tarafından dile getirilmiştir. Bu durum proje tabanlı öğrenmenin bir dezavantajı olarak görülebilir (Çiftçi, 2004).

Sonuç olarak öğretmen ve velilerin proje kavramına dair doğru bilgi sahibi oldukları, velilerin proje çalışmalarını çocuklarının gelişimleri için olumlu buldukları anlaşılmıştır. Proje hazırlama sürecinde öğretmen, öğrenci ve velinin rolleri çok önemlidir. Ancak bu çalışmada bu rollerin bilinçsizce uygulandığında projenin velilerin yarıştığı bir not yükseltme aracı olarak algılandığ1 görülmüştür. Öğretmenlerin Proje Tabanlı Öğrenme yöntemini okullarda sınıf mevcutlarının kalabalık ve müfredatın çok yoğun olduğu olmasından, öğrencilerde genele olarak proje alışkanlığının ve ders zamanın yeterli olmamasından kaynaklanan sorunlar yüzünden uygulanabilir bulmadıkları sonucuna ulaşılmıştır. Buna ek olarak çalışma grubundaki öğretmenlerin derslerinde Proje Tabanlı Öğrenme yöntemini uygulayamadıkları, projeleri değerlendirirken daha çok projeye verilen emeğe ve projelerin kullanışlı olmasına önem verdiği tespit edilmiştir.

\section{5. ÖNERILLER}

Araştırmada öğrencilerin proje süreçlerinde en çok ailelerinden yardım aldıkları görülmüştür. $\mathrm{Bu}$ nedenle proje çalışmalarının daha sağlıklı yürütülebilmesi için ailelerin süreç hakkında yeterli bilgiye sahip olması gerekmektedir. Dolayısıyla okullarda velilere yönelik uzman 
kişilerin yer aldığı bir seminer düzenlenip proje çalışmalarının süreçleri hakkında çocuklarına nerede ve nasıl yardım edeceklerine ilişkin bilgi verilebilir.

Çalışmaya katılan öğretmenlerin proje çalışmalarının daha erken başlaması gerektiği görüşünde oldukları görülmüştür. 2012-2013 eğitim Öğrenme yılında başlanan $4+4+4$ 'lük eğitim sisteminde öğrencilerin daha erken okula başlayabilmektedir. Öğrencilerin proje alışkanlığı kazanabilmesi için seviyelerine göre proje çalışmaları yaptırılabilir. Ayrıca $4+4+4$ 'lük eğitim sisteminde öğrenciler 5. sınıfta seçmeli dersler seçebilmektedirler. Dolayısıyla 'Proje Dersi' adı altında okullarda bir seçmeli ders açılabilir ve çeşitli disiplinlerde öğretmenlerden olan bir proje kurulu oluşturulabilir.

\section{Kaynakça}

Altunışık, R., Çoşkun, R., Yildirim, E. ve Bayraktaroğlu, S. (2010). Sosyal Bilimlerde Araştırma Yöntemleri. (6.Bask1), Sakarya Kitabevi, Sakarya.

Arda, D. (2009). İlk Öğrenme Sınıf Öğretmenlerinin 2005 Öğrenme Programı Ekseninde Ölçme ve Değerlendirme Alanındaki Yeterlilik ve Görüşlerinin Incelenmesi. Yayımlanmamış Yüksek Lisans Tezi, Marmara Üniversitesi Eğitim Bilimleri Enstitüsü, İstanbul.

Ayvacı, H. Ş, ve Er Nas, S. (2009). Fen ve Teknoloji Öğretmenlerinin Proje Tabanlı Öğrenme Yaklaşımının Uygulanabilirliğine Yönelik Görüşleri. Fen, Sosyal ve Çevre Eğitiminde Son Gelişmeler Sempozyumunda Sunulmuş Bildiri, Giresun.

Baki, A. ve Bütüner, S. Ö. (2009). Kırsal Kesimdeki Bir İlk Öğretim Okulunda Proje Yürütme Sürecinden Yansımalar. İlköğretim Online, 8(1), 146-158.

Büyüköztürk, Ş. ; Kılıç, Ç. E.; Akgün, Ö. E. Karadeniz, Ş. ve Demirel. F. (2012). Bilimsel Araştırma Yöntemleri. (13. Baskı), Pegem Akademi Yayınları, Ankara.

Coşkun, M. (2004). Coğrafya Öğretiminde Proje Yaklaşımı. G. Ü. Kırşehir Ĕ̆itim Fakültesi Dergisi, 5(2), 99107.

Çakan, S. (2005). Proje Tabanlı Öğrenme Yaklaşımının Uygulandığı 6. Sınıf Matematik Dersine İlişkin Öğrenci ve Öğretmen Görüşleri (Bir Eylem Araştırması). Yayınlanmamış yüksek lisans tezi. Balıkesir Üniversitesi, Balıkesir.

Çepni, S. (2010). Araştırma ve Proje Çalışmalarına Giriş. (5. Baskı), Celepler Matbaacılık, Trabzon.

Çiftçi, S. (2004). Proje Tabanlı Öğrenme ve Konuda Ülkemizde Yapılan Bazı Araştırmalar. Selçuk Üniversitesi Ĕ̆itim Fakültesi Dergisi, 6(17-18), 75-83.

Çoruhlu, T. Ş.; S, Nas, E. ve Çepni, S. (2009). Fen ve Teknoloji Öğretmenlerinin Alternatif Ölçme Değerlendirme Tekniklerini Kullanmada Karşılaştıkları Problemler: Trabzon Örneği. Yüzüncü Yıl Üniversitesi, Ĕ̆itim Fakültesi Dergisi, 6(1), 122-141.

Dede, Y., ve Yaman, S. (2003). Fen ve Matematik Eğitiminde Proje Çalışmalarının Yeri, Önemin ve Değerlendirilmesi. G.Ü. Gazi Ĕ̆itim Fakültesi Dergisi, 23(1), 117-132 http://www.gefad.gazi.edu.tr/ Lwindow/dosyapdf/2003/1/2003-1-117-132-10yckseldede-scleymanyaman.pdf, Erişim Haziran 2011. 
Demir, K. (2008). Bütünleştirilmiş Öğrenme Programının İşbirliğine Dayalı ve Proje Tabanlı Öğrenme Yaklaşımıyla Uygulanmasının Etkililiği. Yayınlanmamış Doktora Tez. HÜ Sosyal Bilimler Enstitüsü, Ankara.

Demirel, Ö. (2005). Proje Tabanl Öğrenme, Kuramdan Uygulamaya Ĕ̆itimde Program Geliştirme. PegemA Yayıncilik, Ankara.

Erdem, M. (2002). Proje Tabanlı Öğrenme. Hacettepe Üniversitesi Ĕ̆itim Fakültesi Dergisi, 22, 172-179.

Ersoy, A. ve Anagün, S. Ş. (2009). Sınıf Öğretmenlerinin Fen ve Teknoloji Dersi Ödev Sürecine İlişkin Görüşleri. Necatibey Ĕ̆itim Fakültesi Elektronik Fen ve Matematik Eğitimi Dergisi (EFMED), 3(1), 5879.

Esen, O. ve Güneş, G. (2012). İlköğretim Matematik Öğretmenlerinin Proje ve Performans Görevlerine İlişkin Görüşleri. Turkish Journal of Computer and Mathematics Education (TURCOMAT), 3(2), 115130.

Geocities (2007), Proje Tabanlı Öğrenme. http://www.geocities.com/projetabanli/23.html, Erişim Aralık 2010.

Güney, Z. (2010), İlköğretim 4-5 Sinıflarda Verilen Proje ve Performans Ödevleriyle İlgili Öğretmen ve Veli Görüşleri. Yayınlanmamış Yüksek Lisans Tezi, Pamukkale Üniversitesi, Denizli.

Güvey, E. (2009). İlköğretim 1-5. Sinıf Öğrenme Programlarında Yer Alan Proje ve Performans Görevlerine İlişkin Öğretmen ve Veli Görüşleri. Yayınlanmamış Yüksek Lisans Tezi, Osmangazi Üniversitesi Sosyal Bilimler Enstitüsü, Eskişehir.

Hsu, R.C. ve Liu, W.C. (2005). Project Based Learning As Apedagogical Tool For Embedded System Education. 3rd Int, Conf. on Information Technology; Research and Education, 362 - 366.

Kaplan, A. ve Coşkun, Y. (2012). Proje Tabanlı Öğrenme Uygulamalarında Karşılaşılan Güçlükler ve Çözüm Önerilerine Yönelik Bir Eylem Araştırması. Mersin Üniversitesi Eğitim Fakültesi Dergisi, $8(1), 137-159$.

Karakuş, M., (2004). İlköğretim Dördüncü Sınıf Sosyal Bilgiler Dersinde Proje Yaklaşımı İlköğretim Öğrencilerin Sorun Çözme Becerilerine Tutumlarına Akademik Başarılarına ve Kalıcılı̆̆a Etkisi. Yayınlanmamış Doktora tezi, Çukurova Üniversitesi Sosyal Bilimler Enstitüsü, Adana.

Kaymakçı, S. ve Öztürk, T. (2011). Sosyal Bilgiler Öğretmenlerin Proje Çalışmalarıyla İlgili Görüşleri. ODÜ Sosyal Bilimler Enstitüsü Sosyal Bilimler, Araştırmaları Dergisi, 2(3), 103-127.

Korkmaz, H. ve Kaptan, F. (2001). Fen Eğitiminde Proje Tabanlı Öğrenme Yaklaşımı, Hacettepe Üniversitesi Ĕ̆itim Fakültesi Dergisi, 19, 193-200.

Korkmaz, H. ve Kaptan, F. (2002). Fen Eğitiminde Proje Tabanlı Öğrenme Yaklaşımının İlköğretim Öğrencilerinin Akademik Başarı, Akademik Benlik Kavramı ve Çalışma Sürelerine Etkisi. Hacettepe Üniversitesi Ĕ̆itim Fakültesi Dergisi, 22, 91-97.

Kurak, D. (2009). Dördüncü ve Beşinci Sınıf Öğrencilerinin Yaptığı Proje Çalışmalarının Öğretmen ve Öğrenci Görüşlerine Göre Değerlendirilmesi, Yayınlanmamış Yüksek Lisans Tezi, Çukurova Üniversitesi, Adana. 
Kütükte, Z. (2010). İlköğretim Öğretmenlerinin Performans Ve Proje Ödevlerine İlişkin Algı Görüş ve Uygulama Durumları. Yayınlanmamış Yüksek Lisans Tezi, Gaziosmanpaşa Üniversitesi, Sosyal Bilimler Enstitüsü, Tokat.

MEB. (2008). Proje ve Performans Görevleri. B.0.08.İGM.0.08.01-320/443 Say1lı Yazısı, www. meb.gov.tr, Erişim Temmuz 2011.

Öncül, R. (2000). Eğitim ve Eğitim Bilimleri Sözlü̆̆̈̈. Milli Eğitim Bakanlığı Yayınları, İstanbul.

Önen, F; Mertoğlu, H.; Saka, M. ve Gürdal, A. (2010). Hizmet İçi Eğitimin Öğretmenlerin Proje ve Proje Tabanlı Öğrenmeye İlişkin Bilgilerine ve Proje Yapma Yeterliklerine Etkisi: Öpyep Örneği. Ahi Evran Üniversitesi Ĕ̆itim Fakültesi Dergisi, 11(1), 137-158.

Sezgin, G., Çalışkan, S. ,Çallıca, H. ve Erol, M. (2002). Fizik Eğitiminde Projeye Dayalı Laboratuvar Çalışmalarına Yönelik Öğrenci Tutumları. Dokuz Eylül Buca Eğitim Fakültesi Dergisi, 14, 59 - 63.

Şahin, S. (2007). Proje Temelli Öğrenme Ortamında Dersler Arası İşbirliği İle İlgili Öğrenci Görüşlerinin İncelenmesi. Türkiye Sosyal Araştırmalar Dergisi,11(3), 65-76.

Şencan, H. (2005). Sosyal ve Davranışsal Ölçümlerde Güvenilirlik ve Geçerlilik. Seçkin Yayıncılık, Ankara.

Türnüklü, A. (2000). Eğitim Bilim Araştırmalarında Etkin Olarak Kullanılabilecek Nitel Bir Araştırma Tekniği: Görüşme, Kuram ve Uygulamada Ĕ̆itim Yönetimi,6(4), 543-559.

Yıldırım, A. ve Şimşek, H. (2011). Sosyal Bilimlerde Nitel Araştırma Yöntemleri. (8. Basım). Seçkin Kitapevi, Ankara.

Yıldız, N. (2007). Proje Tabanlı Öğrenme Uygulamaları, (online), http://www.erg.sabanciuniv.edu Łiok2004/bildiriler/nadir\%20namik\%20yildiz.doc, Erişim Eylül 2012.

Yurtluk, M. (2005). Proje Tabanlı Öğrenme. Eğitimde Yeni Yönelimler, PegemA Yayıncılık, Ankara.

Yücel, A. (2008). İlköğretim 7. Sinıf Sosyal Bilgiler Dersinde Verilen Performans Ödevleri Hakkında ÖğretmenVeli- Öğrenci Görüşleri. Yayınlanmamış Yüksek Lisans Tezi, Selçuk Üniversitesi, Sosyal Bilimler Enstitüsü, Konya. 


\section{Extended Summary}

The basic aim of science education in Science and Technology classes is to help students solve the problems they encounter and comprehend the principles and concepts (Kaptan ve Korkmaz, 2001). This is possible by providing the students to get high-level mental processes. The Project approach is a learning and teaching approach putting the student in the center of teaching. The basic aim of this approach is to perceive the subject as a problem, to be searched and to bring out solutions by the students (Karakuş, 2004).

In Project Based Learning Method, the students are responible for their learning. The classes in which this method is used enable the students to solve the problems in co-operation and develop their creativity. It is aimed to provide the students to get knowledge and skills while doing the project work. While the teachers are tracking their students, they monitor the possible needs of the students in the Project work or how they solve any problem that they encounter during the Project work (Demirel, 2005; Y1ld1z, 2007). The roles in the process of Project Based Learning are not only shared by the teachers and students. The fundamental part of this Project is formed by the parents (Güvey, 2009). As the parents are to monitor their children and to support them while learning, their role is very big. While preparing the Project work, the teachers should co-operate with students and parents (Kaptan ve Korkmaz, 2001).

Even though there are numerous studies related to application of Project Based Learning Method in Science classes, it has been found out that studies about the views of the teachers and parents in Project Based Learning Method in Science classes are limited. Thus, it is thought in this study that analyzing the views of the parents as well as the views of the teachers and students will help us understand how Project Based Learning Method affects students and parents, and it will contribute to the studies for Science and Technology classes.

The purpose of this study is to analyze the practice process of Project Based Teaching Method in Science and Technology classes. The study was carried out with case study method being one of the qualitative research methods. The data of the study was gathered from 11 Science and Technology Teachers of five state schools in İstanbul in 2010-2011 academic year and 23 parents with semi-structured interviews.

The data were gathered with descriptive analysis method. In order to maintain the ethics of the study, the names of the participants were not given. The parents were coded as V1, V2... ; the teachers as Ö1, Ö2....etc. In order for the relaibility of the coding, the principles of Miles and Huberman were followed (Miles ve Huberman,1984). The relations among the codes were analyzed and similarities and differences were determined. The coding consistency of seperately created categories were evaluated. Then, with the evaluations of researcher and two experts, the responds of the teachers, students and parents were grouped as "Consensus" and "Dissidence". Interrater reliability was determined using the following formula: Reliability equals number of agreements divided by total number of agreements plus disagreements. Percentage of agreement is the ratio of item number on which observers or the evaluators agreed to the number of total evaluation or observation (Türnüklü, 2000). As a result of the calculation, the agreement percentage between the researcher and the two experts were found to be $87,5 \%$ between teachers and parents. In order for the value to accepted as relaible, the agreement percentage is to be above $70 \%$ (Şencan, 2005). With the obtained values, the study can be evaluated to be reliable. 
As a result of the study, it was determined that the common view of the teachers and parents on Projects is to design or create a new production. Önen, Mertoğlu, Saka and Gürdal (2010) studied the knowledge of the teachers for Project and Project Based Learning after in-service training and the results were found to be coherent with the results of our study. Moreover, it can be said that our study coincides with the views of the teachers on the Project Based Learning method in study of Baki and Bütüner (2009). The teachers in the study group were found not to use this method whereas they thought the PBL method should be used in the classes. It was found out that the process starting with the selection of the Project in the school ended at home with the help of the parents of the students. The study revealed out that the teachers evaluated the projects just for an assessment tool. Also, the study revealed out that the teachers found the follow-up forms of Ministry of Education as useless and for this reason, they considered just the efforts of the students while evaluating their projects. The study also revealed out that while some parents found the Project Works to be useful for the students and supported their children, the others stated that their they did their children's projects for score anxiety. The findings obtained from the study showed similarity with the findings obtained from the studies of Kaplan ve Coşkun (2012), Ayvacı ve Er Nas (2009), Ersoy and Anagün (2009), Kurak (2009), Demir (2008), Yücel (2008) and Arda (2009) that the parents involved the Project process too much and took the role of the students in the projects. As the findings coincide, it can be said that our study is supported by the other studies.

As a result, the study revealed out that teachers and parents had accurate information about the project concept, they found projects useful for the improvement of children. Roles of teachers, students and parents are very important in the process of project preparation. However, in this study, it was understood that when these roles were played unconsciously, it became a perception of grade raising for the parents who competed each other. It was understood that teachers did not find Project Based Learning method feasible due to crowded classes, intensive curriculum, insufficient class hours and students' lack of project accustomedness. In addition, teachers in the study group could not implement the ProjectBased Learning method in the classes, focused more on the efforts done for the projects and on the usefulness of the project. 